\title{
Eight years' experience in autologous oocytes vitrification for male factors: efforts to find relevant clinical predictors of oocytes survivability
}

\section{Xiao Fu}

Cheeloo College of Medicine,Shandong University

\section{Xiaojie Liu}

Cheeloo College of Medicine,Shandong University

Jing Li

Cheeloo College of Medicine,Shandong University

\section{Meng Zhang}

Cheeloo College of Medicine,Shandong University

\section{Jingjing Jiang}

Center for Reproductive Medicine,Shandong University

\section{Qianqian Chen}

Center for Reproductive Medicine,Shandong University

\section{Mei Li}

Center for Reproductive Medicine,Shandong University

\section{Jinlong Ma}

Center for Reproductive Medicine,Shandong University

Shanshan Gao ( $\nabla$ sdszgaoshanshan@163.com)

Center for Reproductive Medicine, Shandong University https://orcid.org/0000-0003-4355-8365

\section{Research}

Keywords: oocyte vitrification, survival rate, live birth, obstetric outcomes, blood lipid level

Posted Date: May 24th, 2021

DOI: https://doi.org/10.21203/rs.3.rs-528642/v1

License: (c) (i) This work is licensed under a Creative Commons Attribution 4.0 International License. Read Full License 


\section{Abstract \\ Objective}

The objective of this study was to provides a descriptive analysis of the clinical outcomes achieved in oocyte vitrification in cases of unavailable sperm on oocyte retrieval day, and to find predictors of oocyte survival.

\section{Methods}

This retrospective cohort study used data from a university-affiliated reproductive medicine center. There were 321 cycles carried part or all oocytes vitrification due to unavailability of sperm from March 2009 to October 2017. A descriptive analysis of the clinical outcomes including both fresh embryo transfers and cryopreserved embryos transfers was provided. The ability of an individual parameter to forecast oocyte survival per thawing cycle was assessed by a binary logistic regression analysis. The cumulative probability of live birth (CPLB) was estimated by using the K-M method according to the total number of oocytes consumed in consecutive procedures.

\section{Results}

The average survival rate was $83.13 \%$ (95\% $\mathrm{Cl} 81.81-86.35 \%)$. High-quality embryo rate decreased significantly $(33.33 \%$ vs. $53.75 \%, \mathrm{P}<0.0001)$ comparing to fresh control oocytes. The live birth rate per warmed-oocyte was $4.3 \%$. Reasons for lack of sperm availability on oocyte retrieval day and serum cholesterol level were found to be associated with oocytes survival rate in present study. The KaplanMeier analysis showed no significantly different CPLB between patients $\leq 35$ versus $>35$ years.

\section{Conclusions}

Oocyte vitrification is proved to be an indispensable and effective alternative when lack of available sperm on oocyte retrieval day. Present study provided evidences that the oocytes from infertile population were more likely suffer to vitrification injury. Clinicians need to take this into account when giving suggestions to patients for similar situations. Further studies will be necessary to clarify the correlation between serum sterol lipids levels and human oocyte survivability after vitrification.

\section{Introduction}

Oocyte freezing is no longer considered an experimental method by the American Society for Reproductive Medicine [1]. Oocyte vitrification is gradually becoming a useful adjunct to routine in vitro fertilization (IVF) in various clinical scenarios such as the unavailability of sperm at the time of egg retrieval $[2,3]$, and for couples who do not wish to cryopreserve supernumerary embryos in cases of 
plenty of oocytes are retrieved [4]. Another applicable indication for oocyte vitrification that has now become a reality is the establishment of donor oocyte banks $[5,6]$. Oocytes cryopreservation for deferring child bearing and fertility preservation in cancer patients is also applied in clinic [7-10].

Reports of donor oocyte vitrification of have so far been encouraging. In a sibling cohort study of recipient cycles, similar embryo development has been shown from fresh versus vitrified oocytes [11]. Several well controlled studies about donor oocyte have shown clinical outcomes with vitrified oocytes are comparable to those of fresh oocytes [6,12-14]. A large study of donation program reported by Cobo et al. has demonstrated comparable obstetric and perinatal outcomes from vitrified versus fresh oocytes [15]. These results have confirmed the further application of oocyte vitrification in assisted reproduction treatment for medical indications.

Although oocyte vitrification has been demonstrated as a successful and stable technique in donor program, these information from donation program might provide overly optimistic evidence for oocyte vitrification of medical indications in infertile patients. Different oocyte sources may exist with a different inherent quality that affect the vitrification outcomes[7, 16]. However, reports related to autologous oocytes vitrification in infertile patients was few and inconsistent [10,17]. A study of sibling oocytes from 44 patients undergoing IVF showed reduced rates of fertilization and embryo development after oocyte vitrification [17]. Another study included 128 autologous vitrified/warmed oocytes cycles from IVF cycles demonstrated significantly higher implantation rates ( $43 \%$ vs. $35 \%)$ and clinical pregnancy ( $57 \%$ vs. $44 \%$ ) with vitrified-warmed compared to fresh oocytes [10].

This study aims to describe the outcomes we have achieved from 8 years' experience of oocyte vitrification due to unavailable sperm on oocytes retrieval day. Analysis was carried out to find relevant factors on the oocytes survivability. The reported relatively large data would add to limited information yet available on the clinical application of vitrified autologous oocytes for medical indications.

\section{Materials And Methods}

The ethics committee at the Center for Reproductive Medicine, Shandong University approved this clinical application of oocyte vitrification. Couples chose oocytes cryopreservation because of unavailability of sperm at the time of oocyte retrieval instead of using donor semen. The control group consisted of age and BMI-matched patients, who were undergoing ICSI treatment for male factor infertility (Figure I).

\section{Vitrification kit, Oocyte vitrification-warming and IVF procedures}

This study included two commercially available kits : the MC kit and KT kit, and one Modified kit prepared in our lab. The penetrating cryoprotectants in the MC kit were EG and PROH (MediCult Vitrification Cooling, Copenhagen, Denmark). The Kitazato kit (Kitazato Biopharma Co., Ltd., Shizuoka, Japan) includes EG and DMSO. The Modified kit was made up of three kinds of cryoprotectants: EG (Sigma-Aldrich, St. Louis, MO, 102466, USA), DMSO (Sigma-Aldrich, St. Louis, MO, D2650, USA), and PROH (Sigma-Aldrich, St. Louis, MO, 544324-068, USA). As for the MC kit and KT kit, ES included 7.5\% 
$\mathrm{EG}+7.5 \% \mathrm{PROH}$ (DMSO), and the VS constituted of 15\% EG + 15\% PROH (DMSO) $+0.5 \mathrm{~mol} / \mathrm{L}$ sucrose, per the instructions. The Modified kit was prepared with M-199 (Gibco Invitrogen Corp., Grand Island, NY, USA) as the basal media. A $20 \%$ serum plasma substitute (SPS) (SAGE, Trumbull, CT, USA) was also added. The ES for the Modified kit comprised 7.5\% EG + 3.75\% DMSO + 3.75\% PROH, and the VS comprised $15 \% \mathrm{EG}+7.5 \% \mathrm{DMSO}+7.5 \% \mathrm{PROH}+0.5 \mathrm{~mol} / \mathrm{L}$ sucrose in a M-199 medium with $20 \% \mathrm{SPS}$. [18]

Oocyte vitrification was performed at the room temperature. The oocytes were equilibrated in ES for 5-10 min until they recovered their shape, and then they were placed into the VS for $1 \mathrm{~min}$. Finally, the vitrified oocytes were placed on a CryoLoop (Hampton Research, Laguna Niguel, CA, USA) and immediately immersed in liquid nitrogen. No more than four oocytes were loaded onto each CryoLoop. Oocyte warming was performed at room temperature, except for the first step. The CryoLoop with the vitrified oocytes was taken out of the liquid nitrogen and immediately placed in $1.0 \mathrm{~mol} / \mathrm{L}$ sucrose in a $\mathrm{M}-199+$ $20 \%$ SPS solution at $37^{\circ} \mathrm{C}$ for $1.5-2.0 \mathrm{~min}$. Next, the oocytes were placed in $0.5 \mathrm{~mol} / \mathrm{L}$ sucrose in an $\mathrm{M}-199+20 \%$ SPS solution for $3 \mathrm{~min}$ at the room temperature, after which they were transferred into another M-199 solution with $0.25 \mathrm{~mol} / \mathrm{L}$ sucrose for $3 \mathrm{~min}$. Finally, they were washed in M-199+20\% SPS for 5-10 min while the stage was warmed slowly. After warming, the surviving oocytes were cultured for 2 $\mathrm{h}$ in G-IVF (Vitrolife, Göteborg, Sweden) in an incubator with $37^{\circ} \mathrm{C}, 6 \% \mathrm{CO} 2$ before being inseminated by ICSI. [18] Embryo transfer was performed on Day 2 or Day 3 depending on embryo quality or quantity. No more than 3 embryos were transferred per transfer. The supernumerary embryos were cultured into blastocysts, and high-quality blastocysts were vitrified.

\section{Endometrial preparation and Pregnancy assessment}

All patients used hormone replacement therapy as endometrial preparation protocol, which had been described in previous study [19]. In short, 4-8mg oral oestradiol valerate was administered daily for at least 10 days starting on day $2-5$ of the menstrual cycle. When the endometrial thickness reached $\geq 8$ $\mathrm{mm}$, oral dydrogesterone $20 \mathrm{mg}$ twice daily plus vaginal micronized progesterone $200 \mathrm{mg}$ once daily was initiated on the day of oocyte warming. Clinical pregnancy was determined as the presence of a gestational sac identified by vaginal or abdominal ultrasound 4-5 weeks after embryo transfer (ET). Gestational age, birth weight and congenital malformations outcomes were followed.

\section{Statistical analysis}

The main outcome measurements were survival rate and the cumulative live birth rate (including live birth from fresh ETs and subsequent cryo-ETs) per warming cycle. The secondary outcome measures included laboratory outcomes of vitrified-warmed oocytes, implantation, clinical pregnancy rates, and the delivery rate per fresh embryo transfer and vitrified embryo transfer, as well as gestational age, birth weight and congenital malformations outcomes.

The difference in means and prevalence among the groups were analyzed by Student's t-test for continuous data and Chi square for categorical data. A p value $<0.05$ was considered statistically 
significant. A binary logistic regression model was performed to find predictable parameter of oocyte survival per thawing cycle. The oocyte-to-baby rate was calculated by dividing the number of live births by the total number of oocytes consumed $\times 100$. The cumulative probability of live birth (CPLB) was estimated by the Kaplan-Meier method according to the total number of oocytes consumed in consecutive procedures, including oocytes from cancelled ETs and from fresh or cryo-ETs, until a live birth was achieved.

\section{Results}

Three hundred and twenty-one oocytes vitrified-warmed cycles were carried out from March 2009 to October 2017 due to unavailable sperm on oocytes retrieval day. These oocytes had been vitrified during 2007-2013 previously. The incidence rate was around 0.3\%-0.5\% in all IVF/ICSI cycles during the years. The majority cases for all oocyte vitrification were unavailable sperm from ejaculated sample or surgical sperm extraction (73.23\%), followed by unable to provide ejaculated sample through masturbation (17.72\%) and unexpected absence of male partner (9.05\%) (Table I). The median age of the female patients at oocyte vitrification was 30.24 years $(95 \% \mathrm{Cl} 29.82-30.89)$. The median preservation duration oocyte vitrification was 6.52 weeks $(95 \% \mathrm{Cl} 5.56-7.62)$. The overall oocytes survival rate was $83.13 \%$ (95\% $\mathrm{Cl} 81.81-86.35 \%)$. Data were also obtained from age and BMI matched controls undergoing fresh ICSI cycles for severe male factor with autologous oocytes. Similar fertilization rates shown between vitrified and fresh groups, while high-quality embryo rate decreased significantly (33.33\% vs. $53.75 \%, \mathrm{P}<$ 0.0001 ) in vitrified group. (Table II)

Table III shows information from two groups divided by the median survival rate (91.67\%). The serum total cholesterol (TC)in the $\geq 91.67 \%$ survival rate group was higher. The blood glucose level was also higher in the $\geq 91.67 \%$ survival rate group. There were more cycles due to absolute male factors included in the $\geq 91.67 \%$ survival rate group. And the preservation time was longer in $<91.67 \%$ survival rate group.

Table IV shows comparison between two oocytes vitrification groups divided by different reasons for lack of sperm availability on oocyte retrieval day. The Relative Male Factor group (due to Unable to provide ejaculated sample through masturbation or unexpected absence of partner) presented a higher serum triglyceride (TG). The oocytes survival rate was higher in Absolute Male Factor group (due to unavailable or insufficient sperm from ejaculated sample or surgical sperm).

Table $V$ shows comparison of sibling oocytes between fresh and vitrified groups in part oocytes vitrified cycles. A total of 67 cycles had part MIl oocytes vitrified because of male factors. Forty-one cases inseminated with husband sperm in both fresh oocytes and vitrified oocytes. No significant difference was found between the vitrification and fresh groups of sibling oocytes in fertilization rate $(66.93 \% \mathrm{vs}$. $59.77 \%)$, but few high-quality embryo developed in vitrified group ( $27.68 \% \%$ vs. $53.46 \%)$.

There were 81 vitrified embryo transfer cycles, including 53 DF transfer (i.e. vitrified oocyte and vitrified embryo) cycles and 28 TF (i.e. vitrified oocyte, frozen sperm and vitrified embryo) transfer cycles, which 
yield 22 and 11 neonates respectively. The delivery rate per transfer, gestational age, birth weight and congenital malformations outcomes were similar among groups. (Supplementary Table IV)

One hundred and forty-two babies have been born as a result of 262 fresh ETs and 81 subsequent cryoETs. The cumulative live birth rate per warming cycle was $41.40 \%$. The oocyte-to-baby rate was $4.3 \%$. At the end of present study, 110 blastocysts were still cryopreserved from these oocyte warming cycles included in this work. Suppose the delivery rates are maintained with this cohort, a rough estimation after their use could yield an outcome of 36 additional babies, which would enhance the oocyte-to-baby rate to $5.4 \%$. The Kaplan-Meier analysis showed no significantly different CPLB between patients $\leq 35$ versus > 35 years (Log-rank (Mantel-Cox); $\mathrm{P}=0.231$; Breslow (generalized-Wilcoxon); $\mathrm{P}=0.458$; and Tarone-Ware; $P=0.388$ ). The CPLB improved when more oocytes were warmed and the curve for older patients reached the plateau earlier (with 15 oocytes) than those for young women (with 23 oocytes). (Figure II)

A Binary Logistic regression model was performed to find predictable parameter of oocyte survival per thawing cycle. Several parameters were introduced into the initial model as predictors, including age, BMI, metabolic indicators (includin g TG, TC, HDL, etc.), basic hormones, infertility years, PCOS/non-PCOS, endometriosis/non- endometriosis, ovarian stimulation protocols, reason for lack of sperm availability, vitrification kits, storage duration. As shown by the OR, the effect of the reason for lack of sperm availability was acknowledged, and the effect of serum TC on survival was put forward (Supplementary Table II).

\section{Discussion}

Given that oocyte cryopreservation techniques have changed from slow freezing to vitrification according to the safety and efficacy for the past decade reports [20], oocyte vitrification is gradually applied in assisted reproduction treatment in various clinical scenarios. Especially, oocyte vitrification is becoming an indispensably alternative technique for the couples without enough available sperms at the time of egg retrieval [16].

Our study represents the findings of the largest data set from a single center in China of vitrified autologous oocytes, which were from the couples lack available sperms at the time of egg retrieval. This report comprises 321 oocytes vitrification-warming cycles. A total of 142 healthy babies born from fresh and frozen embryo transfer and the cumulus live birth rate per warming cycle was $44.24 \%$, and 118 cycles $(36.76 \%)$ had successfully taken baby home.

Different oocyte sources, like cancer patients, fertility preservation women, oocytes donors or infertile patients, may exist with different inherent quality that affect the vitrification outcomes $[3,16,19,21]$.This study would add more information, which is not optimistic, to the oocyte vitrification outcomes from infertile patients. Inconsistent with the reports about oocyte recipient cycles [11, 15], the high-quality embryo rate of vitrified oocytes group decreased significantly in comparation to fresh control group in present study (Table II). And fewer high-quality embryos developed in vitrified group in the sibling oocytes comparation from part-vitrified oocytes cycles (Table V). Similar results had also demonstrated by other 
studies from egg-sharing program or autologous oocytes vitrification cycles in infertility women undergoing IVF $[22,23]$. Another supporting result in present study was from comparison between groups of different reasons for lack of sperm availability. The survival rate was significant higher in the absolute male factor group, and the result could be explained that women in this group were relative "fertile" (Table IV). All these outcomes provided evidences that the oocytes from infertile women are more vulnerable to vitrification injury and might not survival through the procedures.

In order to obtain more referential information for clinical work, we tried to find some useful predictors for the success of oocyte vitrification. Age was firstly taken into consideration. However, in present study, no significant difference was discovered between the two age groups ( $\leq 35$ years vs. $>35$ years) in survival rate, fertilization rate and high quality embryo rate (Supplemental Table I). These results were confirmed by the K-M analysis of CPLB according to different age groups. No significantly difference was observed between two age groups (Figure I). This result was inconsistent with previous studies $[6,7,11,15]$, most probably due to the small sample size and characteristic of the older patients involved in present work. Only $50(15.68 \%)$ patients more than 35 years old were included, because most advanced age couples are more inclined to choose donor sperm in case of unavailable sperm on oocyte retrieval day. The average number of retrieved oocytes in this older age group was 11.46 (95\% Cl 9.70-13.22), which indicate a better ovarian reserve of these patients than their peers and further explain the unsignificant difference between two age groups. However, we observed the curve of older patients' curve reached the plateau earlier than young women, which was similar with other studies $[7,11,15]$.

The average survival rate in present study was $83.13 \%(95 \% \mathrm{Cl} 81.81-86.35 \%)$, comparable to the published data range from $68.6-96.8 \%[10,23-26]$ in the literatures. We compared two groups divided by the median survival rate (91.67\%). Statistical differences were found in the serum TC, blood glucose, the proportion of different reasons for lack of sperm availability and preservation time. The results were part consistent to multiple logistic regression analysis. As shown by the $\mathrm{OR}$, the effect of the reason for lack of sperm availability was acknowledged. Another parameter entered the model was serum TC, which had never been analyzed in human oocytes vitrification studies before. A higher serum TC level was found favorable to the oocyte survivability after vitrification. Cholesterol is known to be the major non-polar lipid of mammalian cell membranes [27]. Modulation of plasma membrane cholesterol to increase postcryopreservation survival is currently a new topic in mammals oocytes vitrification [2, 28, 29]. Additionally, several studies had reported that the serum levels of some lipid biomarkers were associated with IVF outcomes[30,31]. Large prospective studies and mechanism researches are needed to clarify if serum sterol lipids levels or other lipidome biomarkers are relevant to the oocyte survivability after vitrification.

Oocyte vitrification efficiency could be defined as the way to a live birth with the lowest number of vitrified oocytes. Although we have obtained a cumulus live birth rate per warming cycle as $44.24 \%$, the oocyte-tobaby rate was only $4.3 \%$ in present study. About one third couples $(36.76 \%)$ had successfully taken babies home. Other studies about oocytes vitrification for medical indications had reported quite different outcomes with oocyte-to-baby rate. Kara et al. reported the live-birth rate per mature oocyte was $3.0 \%$ in oocytes cryopreservation group (<35 years old) [22]. Doyle et al. estimated live birth per warmed oocyte 
as $6.5 \%$ (including predicted live birth from remaining cryopreserved blastocysts) [25]. The data herein would provide more information for clinicians to provide suggestions when patients face with the situation of unavailable sperm on oocytes retrieval day.

The outcomes of live delivery, including gestational age, birth weight, and live birth congenital defect were compared to fresh control group, and no significant difference was discovered. The limited data we could achieve here showed double vitrification (oocyte and embryo vitrification) or triple-cryopreservation (oocyte/embryo vitrification and sperm cryopreservation) had no adverse effect on perinatal outcomes.

The main drawbacks of our study were that few patients $>35$ years were included, and the couples in present study were mostly with severe male factors, which might influence the subsequent embryo quality and pregnancy outcomes. Another drawback was the long time period this retrospective study had included, which might add some variabilities that could play into the data presented. However, we have a relative stable lab team with trained technicians for oocytes vitrification. Furthermore, we had included stimulation protocols and vitrification kits parameters that changed through time into regression model as potential confounders.

In conclusion, Oocyte vitrification is proved to be an indispensable and effective alternative when lack of available sperm on oocyte retrieval day. Present study provided evidences that the oocytes from infertile population were more likely suffer to vitrification injury. Clinicians need to take this into account when giving suggestions to patients for similar situations. Further studies will be necessary to clarify the correlation between serum sterol lipids levels and human oocyte survivability after vitrification.

Table 1

Reasons for lack of sperm availability on the day of oocyte retrieval

\begin{tabular}{|c|c|c|}
\hline Groups & Cycles & Reasons for oocytes vitrification at fresh retrieval \\
\hline $\begin{array}{l}\text { Part-vitrified oocytes } \\
\text { cycles }\end{array}$ & 67 & $\begin{array}{l}\text { insufficient sperm from ejaculated sample or surgical sperm } \\
\text { extraction }\end{array}$ \\
\hline \multirow{3}{*}{$\begin{array}{l}\text { Vitrified-all oocytes } \\
\text { cyles }\end{array}$} & \multirow[t]{3}{*}{254} & Unexpected absence of partner 23(9.05) \\
\hline & & $\begin{array}{l}\text { Unable to provide ejaculated sample through masturbation } \\
45(17.72)\end{array}$ \\
\hline & & $\begin{array}{l}\text { Unavailable sperm from ejaculated sample or surgical sperm } \\
\text { extraction } 186(73.23)\end{array}$ \\
\hline
\end{tabular}


Table 2

Comparison of baseline characteristics, laboratory outcome and clinical outcome between oocytes vitrification group and control group

\begin{tabular}{|c|c|c|c|c|}
\hline \multicolumn{2}{|l|}{ Groups } & $\begin{array}{l}\text { Oocytes } \\
\text { vitrification group }\end{array}$ & Control group & $\begin{array}{l}P \\
\text { value }\end{array}$ \\
\hline \multicolumn{2}{|l|}{ Cycles } & 321 & 321 & \\
\hline \multicolumn{2}{|l|}{ Age $(95 \% \mathrm{Cl})$} & $\begin{array}{l}30.36(29.82- \\
30.89)\end{array}$ & $\begin{array}{l}30.40(29.88- \\
30.91)\end{array}$ & NS \\
\hline \multicolumn{2}{|l|}{ BMI (95\% Cl) } & $\begin{array}{l}22.97(22.57- \\
23.38)\end{array}$ & $\begin{array}{l}23.34(22.96- \\
23.72)\end{array}$ & NS \\
\hline \multirow[t]{3}{*}{ Basal Hormones } & $\mathrm{FSH}(\mathrm{IU} / \mathrm{L})(95 \% \mathrm{Cl})$ & $6.65(6.44-6.86)$ & $6.64(6.43-6.85)$ & NS \\
\hline & LH (IU/L) $(95 \%$ Cl) & $5.37(5.07-5.68)$ & $5.40(5.07-5.73)$ & NS \\
\hline & T0 (ng/dl) $(95 \% \mathrm{Cl})$ & $\begin{array}{l}26.48(24.89- \\
28.08)\end{array}$ & $\begin{array}{l}26.72(25.40- \\
28.05)\end{array}$ & NS \\
\hline \multirow[t]{3}{*}{$\mathrm{COH}$ protocols } & Agonist protocol & 274 & 260 & \multirow[t]{3}{*}{ NS } \\
\hline & Antagonist protocol & 43 & 54 & \\
\hline & others & 4 & 7 & \\
\hline \multicolumn{2}{|c|}{ Oocyte retrieved $(95 \% \mathrm{Cl})$} & $\begin{array}{l}13.99(13.29- \\
14.69)\end{array}$ & $11.13(10.7-11.78)$ & $\begin{array}{l}P< \\
0.0001\end{array}$ \\
\hline \multicolumn{2}{|c|}{ Oocyte warmed $(95 \% \mathrm{Cl})$} & $\begin{array}{l}10.25(9.73- \\
10.77)\end{array}$ & - & \\
\hline \multicolumn{2}{|c|}{ Preservation duration (d) $(95 \% \mathrm{Cl})$} & $\begin{array}{l}195.53(166.31- \\
224.76)\end{array}$ & - & \\
\hline \multicolumn{2}{|c|}{ Vitrified-warmed oocytes } & 3290 & - & \\
\hline \multicolumn{2}{|c|}{ Survival oocytes/ICSI oocytes (\%, 95\% CI) } & $\begin{array}{l}2735 \text { (84.08, } \\
81.81-86.35)\end{array}$ & 2992 & \\
\hline \multicolumn{2}{|c|}{ 2PN zygotes $(\%, 95 \% \mathrm{Cl})$} & $\begin{array}{l}1859(68.27 \\
65.65-70.89)\end{array}$ & $\begin{array}{l}2020(68.03 \\
65.25-70.81)\end{array}$ & NS \\
\hline \multicolumn{2}{|c|}{ D3 high-quality embryo rate $(\%, 95 \% \mathrm{Cl})$} & $\begin{array}{l}632(33.33 \\
30.15-36.51) \#\end{array}$ & $\begin{array}{l}1077(53.75 \\
50.43-57.07)\end{array}$ & $<0.0001$ \\
\hline \multicolumn{2}{|c|}{ Embryos transferred/cycle (95\% Cl) } & $2.08(1.99-2.17)$ & $1.77(1.70-1.84)$ & $<.0001$ \\
\hline
\end{tabular}

Note: * One case favism, one case patent foramen ovale accompany with ventricular septal hypertrophy; \# One case right polycystic kidney disease with left kidney absence, accompany with tetralogy of fallot.

\#Cycles had embryos transfer on D2 in oocyte vitrification group had been excluded in D3 highquality embryos calculation.. 


\begin{tabular}{|c|c|c|c|}
\hline Groups & $\begin{array}{l}\text { Oocytes } \\
\text { vitrification group }\end{array}$ & Control group & $\begin{array}{l}P \\
\text { value }\end{array}$ \\
\hline \multirow{2}{*}{$\begin{array}{l}\text { Implantation rate in fresh embryo transfer } \\
\text { cycle }(\%, 95 \% \mathrm{Cl})\end{array}$} & $24.9(21.2-28.6)$ & $42.86(37.7-48.0)$ & \multirow{2}{*}{$<0.0001$} \\
\hline & D2/D3 transfer & D3/D5 transfer & \\
\hline $\begin{array}{l}\text { Clinical pregnancy per fresh embryo transfer } \\
\text { cycle }(\%, 95 \% \mathrm{Cl})\end{array}$ & $\begin{array}{l}104 / 262(39.69 \\
33.7-45.7)\end{array}$ & $\begin{array}{l}118 / 206(57.28 \\
50.5-64.1)\end{array}$ & $<.0001$ \\
\hline $\begin{array}{l}\text { Early pregnancy loss rate in fresh embryo } \\
\text { transfer cycles }(\%, 95 \% \mathrm{Cl})\end{array}$ & $\begin{array}{l}14 / 104(13.46 \\
6.8-20.1)\end{array}$ & $\begin{array}{l}10 / 118(8.47,3.4- \\
13.6)\end{array}$ & NS \\
\hline Live birth per transfer cycle $(\%, 95 \% \mathrm{Cl})$ & $\begin{array}{l}109 / 262(41.60 \\
35.6-47.6)\end{array}$ & $\begin{array}{l}128 / 206(62.14 \\
55.5-68.8)\end{array}$ & $<.0001$ \\
\hline $\begin{array}{l}\text { Live birth per frozen embryo transfer cycle (\%, } \\
95 \% \mathrm{Cl})\end{array}$ & $\begin{array}{l}33 / 81(40.74 \\
29.8-51.7)\end{array}$ & - & \\
\hline Surplus frozen blastocysts & 110 & 627 & \\
\hline Congenital defect $(\%, 95 \% \mathrm{Cl})$ & $2 *(1.41)(0.6-3.4)$ & $1 \#(0.88)(0-2.3)$ & NS \\
\hline \multicolumn{4}{|c|}{$\begin{array}{l}\text { Note: *One case favism, one case patent foramen ovale accompany with ventricular septal } \\
\text { hypertrophy; \# One case right polycystic kidney disease with left kidney absence, accompany with } \\
\text { tetralogy of fallot. }\end{array}$} \\
\hline \multicolumn{4}{|c|}{$\begin{array}{l}\text { \#Cycles had embryos transfer on D2 in oocyte vitrification group had been excluded in D3 high- } \\
\text { quality embryos calculation.. }\end{array}$} \\
\hline
\end{tabular}


Table 3

Patient and cycle characteristics and CPLB in two oocytes vitrification groups divided by the median survival rate $(91.67 \%)$.

\begin{tabular}{|c|c|c|c|c|}
\hline Groups(survival rate) & & $\geq 91.67 \%$ & $<91.67 \%$ & $\begin{array}{l}P \\
\text { value }\end{array}$ \\
\hline Cycles & & 161 & 160 & \\
\hline Age $(95 \% \mathrm{Cl})$ & & $\begin{array}{l}30.27(29.50- \\
31.09) 4.92\end{array}$ & $\begin{array}{l}30.44(29.70- \\
31.27) 4.87\end{array}$ & NS \\
\hline BMI (95\% Cl) & & $\begin{array}{l}22.80(22.19- \\
23.35) 3.78\end{array}$ & $\begin{array}{l}23.15(22.62- \\
23.69) 3.56\end{array}$ & NS \\
\hline TG & & $\begin{array}{l}1.24(1.07- \\
1.46) 1.29\end{array}$ & $1.19(1.04-1.34) 0.97$ & NS \\
\hline TC & & $\begin{array}{l}4.58(4.42- \\
4.75) 1.07\end{array}$ & $4.33(4.19-4.46) 0.84$ & $<0.05$ \\
\hline HDL & & $\begin{array}{l}1.34(1.30- \\
1.39) 0.31\end{array}$ & $1.30(1.25-1.35) 0.34$ & NS \\
\hline LDL & & $\begin{array}{l}2.93(2.81- \\
3.08) 0.88\end{array}$ & $2.78(2.66-2.90) 0.81$ & NS \\
\hline Glu & & $\begin{array}{l}5.29(5.21- \\
5.38) 0.56\end{array}$ & $5.15(5.05-5.26) 0.65$ & $<0.05$ \\
\hline \multirow[t]{3}{*}{ Basal Hormones } & $\begin{array}{l}\mathrm{FSH}(\mathrm{IU} / \mathrm{L})(95 \% \\
\mathrm{Cl})\end{array}$ & $\begin{array}{l}6.80(6.51- \\
7.12) 1.95\end{array}$ & $6.49(6.22-6.80) 1.86$ & NS \\
\hline & $\begin{array}{l}\mathrm{LH}(\mathrm{IU} / \mathrm{L})(95 \% \\
\mathrm{Cl})\end{array}$ & $\begin{array}{l}5.51(5.13- \\
5.92) 2.57\end{array}$ & $\begin{array}{l}5.24(4.81- \\
5.69) 2.94\end{array}$ & NS \\
\hline & $\begin{array}{l}\text { TO(ng/dl) }(95 \% \\
\text { Cl) }\end{array}$ & $\begin{array}{l}27.04(24.78- \\
29.49) 14.72\end{array}$ & $\begin{array}{l}25.94(23.85- \\
28.33) 14.32\end{array}$ & NS \\
\hline \multirow[t]{3}{*}{$\mathrm{COH}$ protocols } & Agonist protocol & 144 & 130 & \multirow[t]{3}{*}{ NS } \\
\hline & $\begin{array}{l}\text { Antagonist } \\
\text { protocol }\end{array}$ & 16 & 27 & \\
\hline & others & 1 & 3 & \\
\hline \multirow[t]{2}{*}{$\begin{array}{l}\text { Cause of oocytes } \\
\text { vitrification }\end{array}$} & $\begin{array}{l}\text { Absolute Male } \\
\text { factor\# }\end{array}$ & 135 & 118 & \multirow[t]{2}{*}{$<0.05$} \\
\hline & $\begin{array}{l}\text { Relative Male } \\
\text { factor* }\end{array}$ & 26 & 42 & \\
\hline
\end{tabular}

Note: \#Absolute male factor: Unavailable or insufficient sperm from ejaculated sample or surgical sperm.

*Relative male factor: Unable to provide ejaculated sample through masturbation or unexpected absence of partner 


\begin{tabular}{|c|c|c|c|}
\hline Groups(survival rate) & $\geq 91.67 \%$ & $<91.67 \%$ & $\begin{array}{l}P \\
\text { value }\end{array}$ \\
\hline Oocytes retrieved $(95 \% \mathrm{Cl})$ & $\begin{array}{l}13.67(12.71- \\
14.61) 6.17\end{array}$ & $\begin{array}{l}14.31(13.36- \\
15.31) 6.58\end{array}$ & NS \\
\hline Preservation duration (months) $(95 \% \mathrm{Cl})$ & $\begin{array}{l}5.19(4.59- \\
5.91) 4.28\end{array}$ & $\begin{array}{l}7.85(6.27- \\
9.75) 11.68\end{array}$ & $<0.05$ \\
\hline Survival oocytes rate $(\%, 95 \% \mathrm{Cl})$ & $\begin{array}{l}99.26(98.91- \\
99.59) 2.2\end{array}$ & $\begin{array}{l}68.81,(65.56- \\
71.81) 19.69\end{array}$ & $\stackrel{<}{0.0001}$ \\
\hline CPLB, patient $(\%, 95 \% \mathrm{Cl})$ & $68,42.2(34.5-49.9)$ & $74,46.3(38.4-54.1)$ & NS \\
\hline \multicolumn{4}{|c|}{$\begin{array}{l}\text { Note: \#Absolute male factor: Unavailable or insufficient sperm from ejaculated sample or surgical } \\
\text { sperm. }\end{array}$} \\
\hline \multicolumn{4}{|c|}{$\begin{array}{l}\text { *Relative male factor: Unable to provide ejaculated sample through masturbation or unexpected } \\
\text { absence of partner }\end{array}$} \\
\hline
\end{tabular}


Table 4

Patient and cycle characteristics and CPLB in two oocytes vitrification groups divided by different reasons for lack of sperm availability on oocyte retrieval day

\begin{tabular}{|c|c|c|c|c|}
\hline \multicolumn{2}{|c|}{ Groups(survival rate) } & Absolute male factor\# & Relative male factor* & $P$ value \\
\hline \multicolumn{2}{|l|}{ Cycles } & 253 & 68 & \\
\hline \multicolumn{2}{|l|}{ Age $(95 \% \mathrm{Cl})$} & $\begin{array}{l}29.79(29.22- \\
30.42) 4.84\end{array}$ & $\begin{array}{l}30.44(29.70- \\
31.27) 4.87\end{array}$ & NS \\
\hline \multicolumn{2}{|l|}{$\mathrm{BMI}(95 \% \mathrm{Cl})$} & $\begin{array}{l}22.83(22.39- \\
23.29) 3.59\end{array}$ & $\begin{array}{l}23.15(22.62- \\
23.69) 3.56\end{array}$ & NS \\
\hline \multicolumn{2}{|l|}{ TG } & $1.10(1.02-1.19) 0.71$ & $1.6(1.21-2.14) 2.01$ & $<0.05$ \\
\hline \multicolumn{2}{|l|}{ TC } & $4.44(4.31-4.56) 0.95$ & $4.51(4.29-4.77) 1.02$ & NS \\
\hline \multicolumn{2}{|l|}{$\mathrm{HDL}$} & $1.33(1.29-1.37) 0.33$ & $1.28(1.21-1.35) 0.29$ & NS \\
\hline \multicolumn{2}{|l|}{ LDL } & $2.83(2.72-2.95) 0.86$ & $2.96(2.77-3.16) 0.79$ & NS \\
\hline \multicolumn{2}{|l|}{ Glu } & $5.20(5.11-5.28) 0.61$ & $5.32(5.19-5.47) 0.59$ & NS \\
\hline \multirow[t]{3}{*}{$\begin{array}{l}\text { Basal } \\
\text { Hormones }\end{array}$} & $\begin{array}{l}\mathrm{FSH}(\mathrm{IU} / \mathrm{L})(95 \% \\
\mathrm{Cl})\end{array}$ & $6.63(6.40-6.84) 1.77$ & $6.81(6.26-7.42) 2.29$ & NS \\
\hline & $\mathrm{LH}(\mathrm{IU} / \mathrm{L})(95 \% \mathrm{Cl})$ & $5.33(5.03-5.62) 2.45$ & $5.64(4.90-6.56) 3.68$ & NS \\
\hline & $\begin{array}{l}\text { TO(ng/dl) }(95 \% \\
\mathrm{Cl})\end{array}$ & $\begin{array}{l}26.95(25.09- \\
28.79) 14.59\end{array}$ & $\begin{array}{l}24.75(21.69- \\
28.25) 14.21\end{array}$ & NS \\
\hline \multirow[t]{3}{*}{$\mathrm{COH}$ protocols } & Agonist protocol & 217 & 57 & \multirow[t]{3}{*}{ NS } \\
\hline & $\begin{array}{l}\text { Antagonist } \\
\text { protocol }\end{array}$ & 35 & 8 & \\
\hline & others & 1 & 3 & \\
\hline \multicolumn{2}{|c|}{ Oocytes retrieved $(95 \% \mathrm{Cl})$} & $\begin{array}{l}14.05(13.29- \\
14.80) 6.40\end{array}$ & $\begin{array}{l}13.78(12.31- \\
15.29) 6.31\end{array}$ & NS \\
\hline \multicolumn{2}{|c|}{$\begin{array}{l}\text { Preservation duration (months) } \\
(95 \% \mathrm{Cl})\end{array}$} & $6.88(5.79-8.05) 9.43$ & $5.15(3.92-6.74) 6.24$ & NS \\
\hline \multicolumn{2}{|c|}{ Survival oocytes rate $(\%, 95 \% \mathrm{Cl})$} & $\begin{array}{l}85.76(83.24- \\
88.18) 19.70\end{array}$ & $\begin{array}{l}77.85(72.20- \\
82.94) 23.05\end{array}$ & $\begin{array}{l}<.0001 \\
0.00\end{array}$ \\
\hline \multicolumn{2}{|c|}{ CPLB, patient $(\%, 95 \% \mathrm{Cl})$} & $112,44.3(38.1-50.4)$ & 30, $44.1(32.0-56.2)$ & NS \\
\hline \multicolumn{5}{|c|}{$\begin{array}{l}\text { Note: \#Absolute male factor: Unavailable or insufficient sperm from ejaculated sample or surgical } \\
\text { sperm.*Relative male factor: Unable to provide ejaculated sample through masturbation or } \\
\text { unexpected absence of partner }\end{array}$} \\
\hline
\end{tabular}


Table 5

Sibling oocytes comparing in part oocytes vitrified cycles (survival oocytes insemination with husband sperm)

\begin{tabular}{|c|c|c|c|}
\hline Cycles & 41 & & \\
\hline Groups & Fresh oocytes & $\begin{array}{l}\text { Vitrified-warmed } \\
\text { Oocytes }\end{array}$ & $\begin{array}{l}\mathrm{P}- \\
\text { value }\end{array}$ \\
\hline Number of oocytes & 233 & 338 & - \\
\hline Survival oocytes (\%, 95\% Cl) & - & $\begin{array}{l}299(90.24,84.20- \\
96.28)\end{array}$ & - \\
\hline 2PN zygotes $(\%, 95 \% \mathrm{Cl})$ & $\begin{array}{l}143(59.77,48.63- \\
70.91)\end{array}$ & $\begin{array}{l}207(66.93,57.99- \\
75.88)\end{array}$ & NS \\
\hline D2 transfer cycles (NO. embryos) & $10(16)$ & $9(23)$ & - \\
\hline D3 transfer cycles (NO. embryos) & $18(28)$ & $20(41)$ & - \\
\hline D3 high-quality embryos* (\%, 95\% Cl) & $\begin{array}{l}53 / 126(53.46 \\
39.05-67.86)\end{array}$ & $\begin{array}{l}53 / 177(27.68 \\
18.34-37.02)\end{array}$ & $\dot{0} 0001$ \\
\hline $\begin{array}{l}\text { Live birth per oocyte retrieval cycle or } \\
\text { warmed cycle }(\%, 95 \% \mathrm{Cl})\end{array}$ & $4 / 41(9.5,3.0-18.8)$ & $\begin{array}{l}17 / 41(40.48,25.0- \\
56.0)\end{array}$ & $\dot{0} 0001$ \\
\hline
\end{tabular}

\section{Declarations}

\section{Acknowledgments}

The authors thank the medical workers in the research group at the Reproductive Hospital of Shandong University for giving the experience for this study and also thank the information engineer for assembling the data for this study.

\section{Authors' contributions}

SG and JM contributed to the study concept and design of this study. XF and XL analyzed data and drafted the paper. $\mathrm{JL}$ and $\mathrm{MZ}$ contributed to the review and the revision of the manuscript. All authors approved the final submitted and published versions.

\section{Funding}

This study was supported by The National Key Research and Development Program of China (2016YFC1000202 and 2018YFC1002804).

\section{Availability of data and materials}


The datasets used and/or analyzed during the current study are available from the corresponding author on reasonable request.

Ethics approval and consent to participate

This study was approved by the Institutional Review Board of Center for Reproductive Medicine Affiliated to Shandong University. Written informed consent was waived due to the retrospective nature, and patients' data were used anonymously.

Consent for publication

Not applicable.

Competing interests

The authors declare that they have no competing interests.

\section{References}

1. Mature oocyte cryopreservation: a guideline.Fertil Steril 2013, 99:37-43.

2. Chen X, Dong H, Cheng M, Wang Q, Jin Y: Addition of cholesterol loaded cyclodextrin prior to GVphase vitrification improves the quality of mature porcine oocytes in vitro.Cryobiology 2019, 90:5462.

3. Cobo A, Diaz C: Clinical application of oocyte vitrification: a systematic review and meta-analysis of randomized controlled trials. Fertil Steril 2011, 96:277-285.

4. Lucena E, Bernal DP, Lucena C, Rojas A, Moran A, Lucena A: Successful ongoing pregnancies after vitrification of oocytes. Fertil Steril 2006, 85:108-111.

5. Cai LB, Qian XQ, Wang W, Mao YD, Yan ZJ, Liu CZ, Ding W, Huang J, Chai DC, Chian RC, Liu JY: Oocyte vitrification technology has made egg-sharing donation easier in China.Reprod Biomed Online 2012, 24:186-190.

6. Cobo A, Garrido N, Pellicer A, Remohí J: Six years' experience in ovum donation using vitrified oocytes: report of cumulative outcomes, impact of storage time, and development of a predictive model for oocyte survival rate.Fertil Steril 2015, 104:1426-1434.e1421-1428.

7. Cobo A, García-Velasco J, Domingo J, Pellicer A, Remohí J: Elective and Onco-fertility preservation: factors related to IVF outcomes. Hum Reprod 2018, 33:2222-2231.

8. Dolinko AV, Farland LV, Missmer SA, Srouji SS, Racowsky C, Ginsburg ES: Responses to fertility treatment among patients with cancer: a retrospective cohort study. Fertil Res Pract 2018, 4:3.

9. Domingo J, Garcia-Velasco JA: Oocyte cryopreservation for fertility preservation in women with cancer.Curr Opin Endocrinol Diabetes Obes 2016, 23:465-469.

10. Doyle JO, Richter KS, Lim J, Stillman RJ, Graham JR, Tucker MJ: Successful elective and medically indicated oocyte vitrification and warming for autologous in vitro fertilization, with predicted birth 
probabilities for fertility preservation according to number of cryopreserved oocytes and age at retrieval.Fertil Steril 2016, 105:459-466.e452.

11. Cobo A, Kuwayama M, Pérez S, Ruiz A, Pellicer A, Remohí J: Comparison of concomitant outcome achieved with fresh and cryopreserved donor oocytes vitrified by the Cryotop method.Fertil Steril 2008, 89:1657-1664.

12. Gala A, Ferrières-Hoa A, Loup-Cabaniols V, Fournier A, Anav M, Brunet $C$, Bringer-Deutsch $S$, Ranisavljevic N, Brouillet S, Hamamah S: Closed vitrification system and egg donation: Predictive factors of oocyte survival and pregnancy.J Gynecol Obstet Hum Reprod 2020, 49:101687.

13. De Munck N, Belva F, Van de Velde H, Verheyen G, Stoop D: Closed oocyte vitrification and storage in an oocyte donation programme: obstetric and neonatal outcome. Hum Reprod 2016, 31:1024-1033.

14. Seshadri S, Saab W, Exeter H, Drew E, Petrie A, Davies M, Serhal P: Clinical outcomes of a vitrified donor oocyte programme: A single UK centre experience.Eur J Obstet Gynecol Reprod Bio/2018, 225:136-140.

15. Cobo A, Serra V, Garrido N, Olmo I, Pellicer A, Remohí J: Obstetric and perinatal outcome of babies born from vitrified oocytes. Fertil Steril 2014, 102:1006-1015.e1004.

16. Cil AP, Seli E: Current trends and progress in clinical applications of oocyte cryopreservation.Curr Opin Obstet Gynecol 2013, 25:247-254.

17. Forman EJ, Li X, Ferry KM, Scott K, Treff NR, Scott RT, Jr.: Oocyte vitrification does not increase the risk of embryonic aneuploidy or diminish the implantation potential of blastocysts created after intracytoplasmic sperm injection: a novel, paired randomized controlled trial using DNA fingerprinting.Fertil Steril 2012, 98:644-649.

18. Li M, Wang MM, Liu H, Wu KL, Ma SY, Li C, Zhao HB, Chen ZJ: Comparison of the Developmental Potential and Clinical Results of In Vivo Matured Oocytes Cryopreserved with Different Vitrification Media.Chin Med J (Engl) 2015, 128:3029-3034.

19. Shanshan G, Mei L, Keliang W, Yan S, Rong T, Zi-Jiang C: Effect of different rehydration temperatures on the survival of human vitrified-warmed oocytes.J Assist Reprod Genet 2015, 32:1197-1203.

20. Boldt J: Current results with slow freezing and vitrification of the human oocyte.Reprod Biomed Online 2011, 23:314-322.

21. De Santis L, Cino I, Coticchio G, Fusi FM, Papaleo E, Rabellotti E, Brigante C, Borini A, Ferrari A: Objective evaluation of the viability of cryopreserved oocytes.Reprod Biomed Online 2007, 15:338345.

22. Goldman KN, Noyes NL, Knopman JM, McCaffrey C, Grifo JA: Oocyte efficiency: does live birth rate differ when analyzing cryopreserved and fresh oocytes on a per-oocyte basis? Fertil Steril 2013, 100:712-717.

23. Braga DP, Setti AS, Figueira RC, Azevedo Mde C, laconelli A, Jr., Lo Turco EG, Borges E, Jr.: Freeze-all, oocyte vitrification, or fresh embryo transfer? Lessons from an egg-sharing donation program. Fertil Steril 2016, 106:615-622. 
24. Chang CC, Elliott TA, Wright G, Shapiro DB, Toledo AA, Nagy ZP: Prospective controlled study to evaluate laboratory and clinical outcomes of oocyte vitrification obtained in in vitro fertilization patients aged 30 to 39 years. Fertil Steril 2013, 99:1891-1897.

25. Rienzi L, Romano S, Albricci L, Maggiulli R, Capalbo A, Baroni E, Colamaria S, Sapienza F, Ubaldi F: Embryo development of fresh 'versus' vitrified metaphase II oocytes after ICSI: a prospective randomized sibling-oocyte study. Hum Reprod 2010, 25:66-73.

26. Yoon TK, Kim TJ, Park SE, Hong SW, Ko JJ, Chung HM, Cha KY: Live births after vitrification of oocytes in a stimulated in vitro fertilization-embryo transfer program. Fertil Steril 2003, 79:1323-1326.

27. Ikonen E: Cellular cholesterol trafficking and compartmentalization.Nat Rev Mol Cell Biol 2008, 9:125138.

28. Arcarons N, Morató R, Vendrell M, Yeste M, López-Bejar M, Rajapaksha K, Anzar M, Mogas T:

Cholesterol added prior to vitrification on the cryotolerance of immature and in vitro matured bovine oocytes. PLoS One 2017, 12:e0184714.

29. Buschiazzo J, Ríos GL, Canizo JR, Antollini SS, Alberio RH: Free cholesterol and cholesterol esters in bovine oocytes: Implications in survival and membrane raft organization after cryopreservation.PLOS One 2017, 12:e0180451.

30. Chiu YH, Karmon AE, Gaskins AJ, Arvizu M, Williams PL, Souter I, Rueda BR, Hauser R, Chavarro JE: Serum omega-3 fatty acids and treatment outcomes among women undergoing assisted reproduction. Hum Reprod 2018, 33:156-165.

31. Jungheim ES, Frolova Al, Jiang H, Riley JK: Relationship between serum polyunsaturated fatty acids and pregnancy in women undergoing in vitro fertilization.J Clin Endocrinol Metab 2013, 98:E13641368.

\section{Figures}



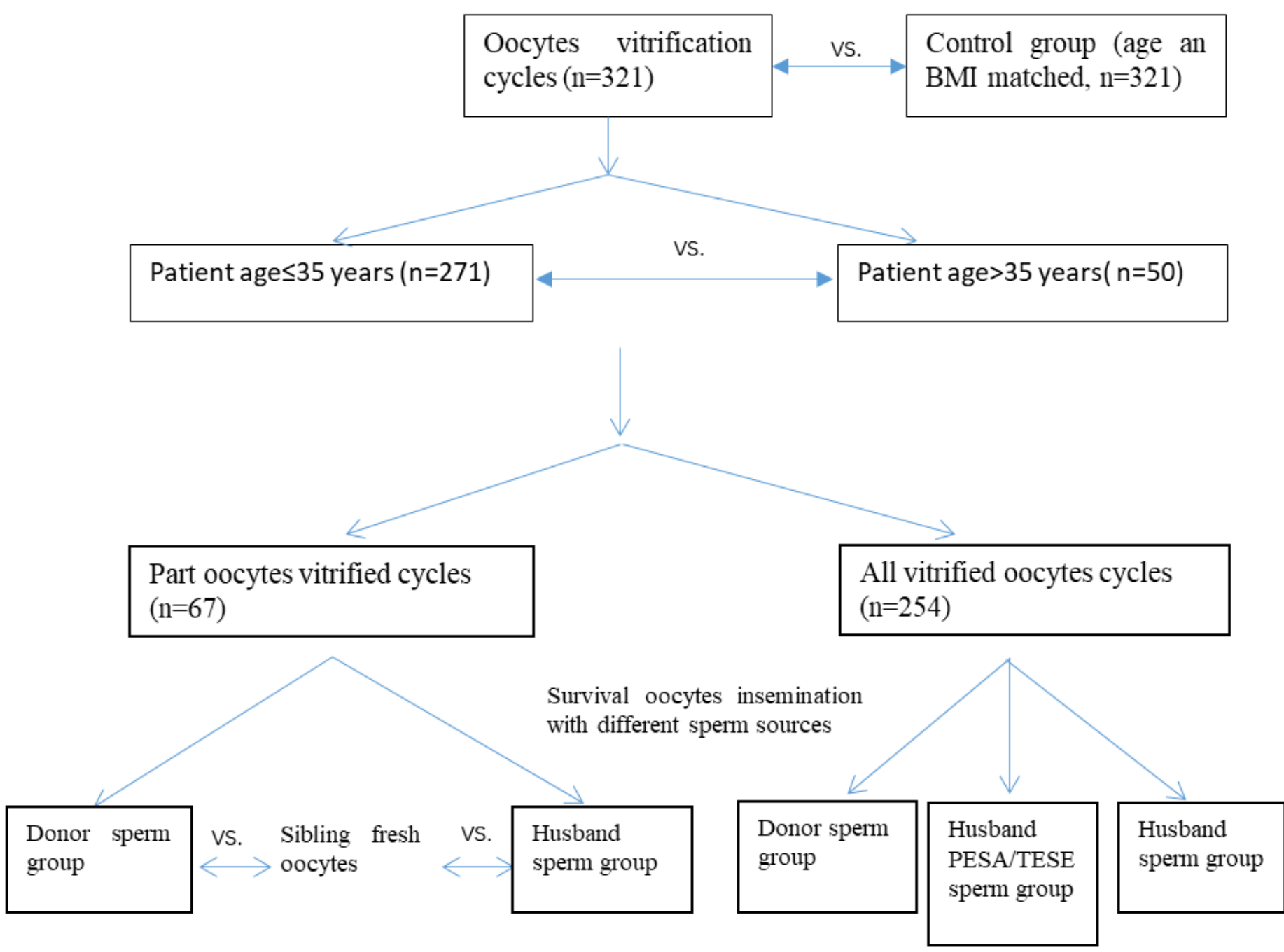

Figure 1

Description of experimental groups and comparisons 


\section{Cumulative probability of live birth}

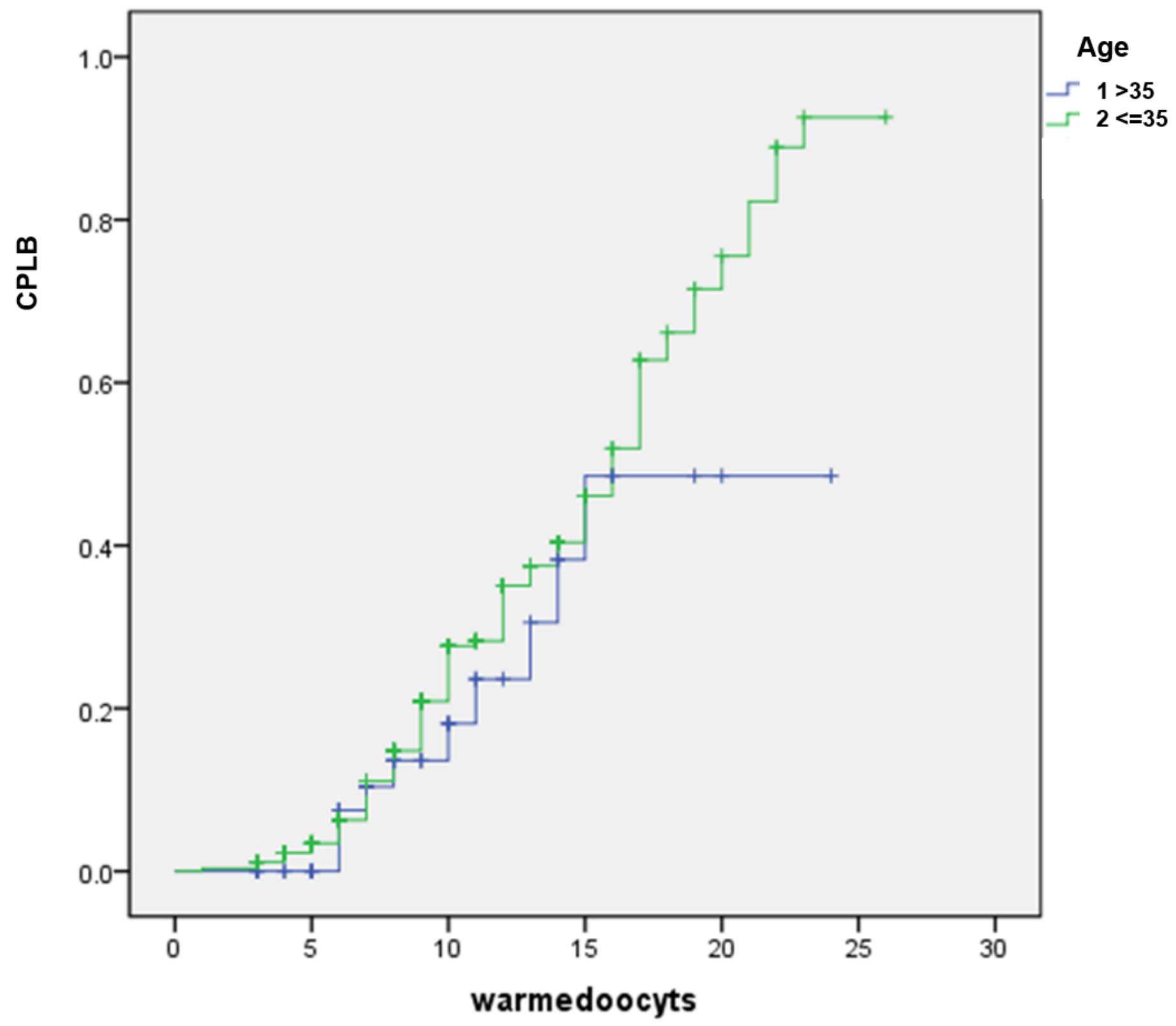

Figure 2

The cumulative probability of live birth according to age ( $\leq 35$ year vs. $>35$ year) and number of oocytes consumed

\section{Supplementary Files}

This is a list of supplementary files associated with this preprint. Click to download. 
- SupplementaryMaterialforReview.docx 